\title{
Evaluation of direct antiviral activity of the Deva-5 herb formulation and extracts of five Asian plants against influenza A virus $\mathrm{H} 3 \mathrm{~N} 8$
}

Namsrai Oyuntsetseg ${ }^{1 *}$, Maxim A Khasnatinov², Perenlei Molor-Erdene', Janchiv Oyunbileg ${ }^{3}$, Aleksander V Liapunov², Galina A Danchinova², Sanduijav Oldokh', Jigden Baigalmaa ${ }^{1}$ and Chimedtseren Chimedragchaa ${ }^{4}$

\begin{abstract}
Background: The herb formulation Deva- 5 is used in traditional medicine to treat acute infectious diseases. Deva-5 is composed of five herbs: Gentiana decumbens L., Momordica cochinchinensis L., Hypecoum erectum L., Polygonum bistorta L., and Terminalia chebula Retz. Deva-5 and its five components were investigated for in vitro antiviral activity against avian influenza A virus subtype H3N8.
\end{abstract}

Methods: The water extracts of the herbal parts of G. decumbens, H. erectum and P. bistorta, the seeds of $T$. chebula and M. cochinchinensis and Deva-5 were prepared by boiling and clarified by low-speed centrifugation and filtration. To assess the antiviral properties, avian influenza virus isolate A/Teal/Tunka/7/2010(H3N8) was incubated at $37^{\circ} \mathrm{C}$ for $30 \mathrm{~min}$ in the presence and absence of the extracts of five plants and DEVA-5 in various concentrations. Subsequently, the concentration of infectious virus in each sample was determined by plaque assays. Neutralisation indexes and $90 \%$ plaque reduction concentrations were estimated for each extract, and the significance of the data was evaluated using statistical methods.

Results: The extracts of $G$. decumbens, H. erectum, P. bistorta and Deva- 5 demonstrated no significant toxicity at concentrations up to $2 \%$, whereas extracts of T. chebula and $M$. cochinchinensis were well-tolerated by Madin-Darby canine kidney cells at concentrations up to $1 \%$. The extracts of $H$. erectum, $M$. cochinchinensis and $T$. chebula reduced the titre of A/Teal/Tunka/7/2010 (H3N8) by approximately five-fold ( $p \leq 0.05)$. The other three extracts did not significantly reduce the infectivity of the virus. The plaque reduction neutralisation tests revealed that none of the extracts tested were able to inhibit formation of plaques by $90 \%$. However, three extracts, H. erectum, T. chebula and M. cochinchinensis, were able to inhibit formation of plaques by more than 50\% at low dilutions from 1:3 to 1:14. The $T$. chebula extract had a concentration-dependent inhibitory effect.

Conclusions: For the first time, the consistent direct antiviral action of the extracts of $H$. erectum, T. chebula and $M$. cochinchinensis was detected. These extracts significantly reduced the infectivity of influenza A virus H3N8 in vitro when used at high concentrations (0.5-1\%). However, Deva- 5 itself and the remainder of its components did not exhibit significant antiviral action. The results suggest that $H$. erectum, T. chebula and M. cochinchinensis plants contain substances with direct antiviral activity and could be promising sources of new antiviral drugs.

Keywords: Gentiana decumbens, Momordica cochinchinensis, Hypecoum erectum, Polygonum bistorta, Terminalia chebula, Deva-5, Influenza A virus, H3N8, Antivirals

\footnotetext{
* Correspondence: oyuntsetseg.n@mnums.edu.mn

${ }^{1}$ Institute of Traditional Medicine, Mongolian National University of Medical

Sciences, Zorig str, Sukhbaatar district, Ulaanbaatar, Mongolia

Full list of author information is available at the end of the article
} 


\section{Background}

Influenza A virus (IAV) is important pathogen that causes acute disease in humans and domestic animals. In Mongolia, during the 2010/2011 influenza season, an average of 1,232 influenza-like illnesses per 10,000 people was recorded, comprising $5.8 \%$ of all recorded outpatient visits [1].

The IAV belongs to the family Orthomyxoviridae and is currently divided into subtypes according to the structure of the major virion proteins - haemagglutinin (HA) and neuraminidase (NA). To date, up to 17 subtypes of HA and up to 10 subtypes of NA have been differentiated [2]. Birds are the natural host of the virus and can harbour any subtype of IAV. However, from time to time, some avian IAVs adapt to mammalian hosts, posing a serious threat to healthcare and the economy [3]. For example, the human-avian reassortant virus $\mathrm{H} 3 \mathrm{~N} 2$ entered the human population in 1968 and is currently the major agent of seasonal flu, causing 3-5 million human cases of acute respiratory illness worldwide [3,4]. Equine IAV (H3N8) causes acute disease in horses and regularly diverges from avian IAV, most recently occurring in 1989 [5]. At present, equine IAV affects 2.1 million Mongolian horses and critically impacts the economy and nomadic livelihood in Mongolia [6].

The herb formulation Deva-5 is used in traditional medicine to treat acute infectious diseases [7]. Deva-5 is composed of five different herbs: Gentiana decumbens L. (26.3\%), Momordica cochinchinensis L. (18.4\%), Hypecoum erectum L. (15.7\%), Polygonum bistorta L. (23.6\%) and Terminalia chebula Retz. (15.7\%) [8].

G. decumbens is traditionally used to cure infectious diseases and stomach disorders [9]. It has been reported to have potent anti-oxidant activity [10]. In traditional medicine, $M$. cochinchinensis is used to treat liver, stomach and kidney disorders, and it has detoxifying and antipyretic properties [9]. The anti-inflammatory, anti-oxidant, and antitumor activities of $M$. cochinchinensis have been demonstrated [11-13]. H. erectum is used to cure infectious disorders in traditional medicine, and it has antibacterial, antinociceptive and antipyretic properties [9]. Studies have shown antibacterial and anti-inflammatory activities of $H$. erectum $[14,15]$. P. bistorta reduces oedema and is used to treat lung disorders in traditional medicine [9]. Its antiinflammatory effect has been reported [16]. T. chebula has been described in books of traditional medicine as a panacea and is used for the treatment of most diseases, especially stomach disorders [9]. T. chebula has been most extensively studied among the constituents of Deva-5. It has a wide spectrum of pharmacological and medicinal activities that include anti-oxidative, antibacterial, antiviral, anti-inflammatory and immunomodulatory activities $[17,18]$. Recently, it was shown to protect epithelial cells against damage caused by influenza A virus [19].
In the present study, we probed the direct antiviral effects of Deva-5 and its constituents against the recently isolated avian influenza virus $\mathrm{H} 3 \mathrm{~N} 8$, which is homologous in its HA structure to human $\mathrm{H} 3 \mathrm{~N} 2$ and equine H3N8 influenza viruses of epidemiological and veterinary importance.

\section{Methods}

\section{Plant material and preparation of extracts}

The aerial parts of G. decumbens, $H$. erectum, and P. bistorta were obtained from Tuv province in Mongolia; seeds of $M$. cochinchinensis and T. chebula were imported from China. The Deva-5 herb formulation and its five components were prepared in the traditional medical factory of the Traditional Medical Science Technology and Production Corporation of Mongolia. The plants were identified by a botanist at the Institute of Traditional Medicine, and voucher specimens were deposited and are publicly available at the Herbarium of Institute of Traditional Medicine, Mongolian National University of Medical Sciences (abbreviation of the herbarium, tserentsoo@mnums.edu.mn).

To minimise the effect of the preparation procedures on the bioactive compounds in the herbs, the extracts were prepared with boiling water. Briefly, $30 \mathrm{~g}, 10 \mathrm{~g}, 2 \mathrm{~g}$ or $1 \mathrm{~g}$ of each plant material was suspended in $200 \mathrm{ml}$ of sterile double distilled water $\left(\mathrm{ddH}_{2} \mathrm{O}\right)$ and boiled at low heat for 15-30 $\mathrm{min}$. When the total volume of the extract had reached a volume slightly less than $100 \mathrm{ml}$, the extracts were measured and made up to $100 \mathrm{ml}$ with sterile $\mathrm{ddH}_{2} \mathrm{O}$ if necessary. Then, the extracts were filtered through a sterile gauze filter and finally through sterile $0.45 \mu \mathrm{m}$ filter paper. All extraction and purification work was done aseptically and the resulting extracts were stored at $+4^{\circ} \mathrm{C}$ for $1-2 \mathrm{~h}$ before the experiments.

\section{Cells}

Madin-Darby canine kidney (MDCK) cells were purchased from BioloT (Saint Petersburg, Russian Federation). Cells were maintained at $37^{\circ} \mathrm{C}$ in DMEM culture media (with L-glutamine) supplemented with $10 \%$ foetal calf serum, 25 mM HEPES and $0.2 \%$ bovine serum albumin. The cells were sub-cultured twice a week using $0.25 \%$ trypsin solution supplemented with $0.5 \mathrm{mM}$ EDTA (BioloT, Saint Petersburg, Russian Federation).

\section{Virus maintenance and plaque titration assay}

Avian influenza virus (AIV) isolate A/Teal/Tunka/7/ 2010(H3N8) was obtained from cloacal swabs of European teal (Anas crecca) sampled in eastern Siberia in 2010. The virus underwent three passages in chicken embryos and one passage in MDCK cells. The stock virus was propagated in DMEM culture media supplemented with $25 \mathrm{mM}$ HEPES, $0.2 \%$ bovine serum 
albumin, $2 \mu \mathrm{g} / \mathrm{ml}$ of TPCK-trypsin and antibiotics, then aliquoted and stored at $-80^{\circ} \mathrm{C}$ until use [20]. Infected cell cultures were incubated at $37^{\circ} \mathrm{C}$ in humidified $5 \%$ $\mathrm{CO}_{2}$. Plaque titrations were performed in quadruplicates according to Gaush and Smith [21], with minor modifications. Briefly, the virus suspension was serially 10 -fold diluted using serum-free DMEM up to $10^{-8}$, and $250 \mu \mathrm{l}$ of each dilution was inoculated in corresponding wells of a 24-well plate with $90 \%$ confluent MDCK cells. After $1 \mathrm{~h}$ of adsorption at room temperature, the inocula were discarded, and the cells were washed with serum-free DMEM and overlaid with DMEM supplemented with 25 mM HEPES, $0.2 \%$ bovine serum albumin, $2 \mu \mathrm{g} / \mathrm{ml}$ of TPCK-trypsin, antibiotics and $1 \%$ low melting point agarose (Sigma). The plates were incubated at room temperature until the overlay media became solid, and then they were placed in a $5 \% \mathrm{CO}_{2}$ humidified atmosphere at $37^{\circ} \mathrm{C}$. On day 3 post infection, the monolayers were fixed with a $10 \%$ solution of formalin in phosphate buffered saline (PBS, pH 7.4) overnight and plaques were visualised by staining with a $0.05 \%$ solution of crystal violet in $\mathrm{ddH}_{2} \mathrm{O}$. The plaques were counted, and virus concentration was expressed as the number of plaque forming units in one millilitre of suspension (PFU/ml).

\section{RNA extraction, reverse transcription and PCR}

The virus RNA was extracted from $100 \mu$ of allantoic fluid using a RiboPrep RNA extraction kit (Amplisens, Moscow). The RNA pellet was dissolved in $50 \mu \mathrm{l}$ of RNA dilution buffer, and $10 \mu \mathrm{l}$ of RNA solution was used to synthesise the cDNA with random hexamers using the Reverta-L kit (Amplisens, Moscow) according to the manufacturer's manual. The RT reaction mixture was incubated at $37^{\circ} \mathrm{C}$ for $1 \mathrm{~h}$, followed by $15 \mathrm{~min}$ at $70^{\circ} \mathrm{C}$. The effectiveness of cDNA synthesis was evaluated by a PCR assay with the primers CU-MF 5`TGATCTTCTTGA AAATTTGCAG 3` and CU-MR 5`TGTTGACAAAATGACCATCG 3` to amplify a 276-bp fragment of the gene for the matrix $(\mathrm{M})$ protein with high sensitivity, as described by Payungporn et al. [22]. The subtype of HA was identified using an H1-H15-specific RT-PCR assay designed by Tsukamoto et al. [23]. Briefly, 15 separate PCR reactions were run with subtype-specific primer pairs. The primers were synthesised commercially according to the previously mentioned report [23]. Each PCR reaction was performed in volume of $25 \mu \mathrm{l}$ and contained $2.5 \mu \mathrm{l}$ of cDNA, $2.5 \mu$ of PCR buffer (Sigma), $10 \mathrm{mM}$ dNTP (New England Biolabs), $10 \mathrm{pmol}$ of each primer, $1.5 \mathrm{mM} \mathrm{MgSO}_{4}$ and $0.5 \mu \mathrm{l}$ of DiaTaq DNA polymerase (Amplisens, Moscow). The conditions of PCR included initial denaturation at $94^{\circ} \mathrm{C}$ for $5 \mathrm{~min}$ followed by 35 cycles of denaturation at $94^{\circ} \mathrm{C}$ for $30 \mathrm{sec}$, annealing at $50^{\circ} \mathrm{C}$ for $30 \mathrm{sec}$ and elongation at $72^{\circ} \mathrm{C}$ for $30 \mathrm{sec}$. Final elongation was performed at $72^{\circ} \mathrm{C}$ for $5 \mathrm{~min}$. The resulting PCR products were resolved on a $2 \%$ agarose gel with ethidium bromide staining.

\section{Nucleotide sequencing and phylogenetic analysis}

The isolate A/Teal/Tunka/7/2010 has not been previously identified by serological or genetic methods. Therefore, we confirmed the HA subtype identification and identified the NA subtype by phylogenetic analysis of nucleotide sequences of the $\mathrm{HA}$ and NA genes in comparison with reference sequences representing all known subtypes of influenza A [24].

The fragments of genes coding for HA and NA were amplified using the procedure developed by Hoffmann et al. [25]. A detailed list of primers used in this study is given in Table 1 . The PCR reaction was performed in a volume of $100 \mu \mathrm{l}$ as described above. The PCR products were resolved on a $0.8 \%$ agarose gel, excised from the gel and purified with the QIAgen PCR purification kit (Qiagen). The PCR products were directly sequenced using Sanger's dideoxy termination method, and obtained nucleotide sequences were deposited in GenBank with accession numbers KF790581 and KF790582 for the HA and NA gene fragments, respectively. Sequences were edited and aligned using BioEdit software.

The set of reference sequences included the GenBank accession numbers AF091309 (H1), AY633196 (H2N3), L11129 (H2N9), AY531037 (H3), D90302 (H4), U20460 (H5), AY968676 (H6), U20462 (H7), AB289343 (H8), AY206671 (H9), CY087832 (H10), D90306 (H11), AB288334 (H12), AF250362 (N1), AJ574904, DQ067439 (N2), AY207522, AY207524, AY207513 (N3), CY003986, CY004180 (N4), EU429794 (N5), AY207549 (N6), AB472061, CY014993 (N7), L06587 (N8) and AB292780 (N9). The phylogenetic analysis was performed with the neighbour-joining method; the estimation of evolutionary distances was made based on the Tamura-Nei 93 model of evolution [26], and the significance of the obtained models was evaluated by bootstrap analysis with 1000 replications. The clusters supported by a $70 \%$ bootstrap value and higher were assumed to be significant. The Mega 5 program package was used to perform the phylogenetic analysis.

\section{Evaluation of the toxicity of herb extracts in MDCK cells} MDCK cells were grown to confluence in 96-well culture plates (Sarstedt, USA) and treated in quadruplicate with serial two-fold dilutions of herb extracts in maintenance media, i.e. from $15 \%$ to $0.03 \%$. A series of twofold dilutions of PBS ( $\mathrm{pH} 7.4$ ) in maintenance media was used as the control. Plates were incubated at $37^{\circ} \mathrm{C}$ in $5 \%$ $\mathrm{CO}_{2}$ for 7 days. The morphology and viability of cells was evaluated daily using light microscopy. By the seventh day of incubation, cells were washed with sterile PBS $\left(\mathrm{pH}\right.$ 7.4) prewarmed to $37^{\circ} \mathrm{C}$, fixed with $10 \%$ formalin and 
Table 1 Primers used to amplify and sequence the fragments of HA and NA genes of A/Teal/Tunka/7/2010 (H3N8)

\begin{tabular}{llll}
\hline Title & Sequence, $\mathbf{5}^{\prime} \mathbf{-} \mathbf{>} \mathbf{3}^{\prime}$ & Target gene & References \\
\hline H3-919 F & gyatyactccwaatggaagc & HA & Tsukamoto et al. [23] \\
Bm-NS-890R & atatcgtctcgtattagtagaaacaagggtgtttt & HA & Hoffmann et al. [25] \\
Bm-NA-1 L & tattggtctcagggagcaaaagcaggagt & NA & Hoffmann et al. [25] \\
Bm-NA-1413R & atatggtctcgtattagtagaaacaaggagttttt & NA & Hoffmann et al. [25] \\
\hline
\end{tabular}

stained with crystal violet as described earlier. The stained monolayers were dried, and the stain was extracted with $100 \mu \mathrm{l}$ of pure methanol. The number of surviving cells was evaluated by measuring the optical density of the corresponding extract at a wavelength of $630 \mathrm{~nm}$ using an Immunochem 2100 microplate spectrophotometer (High Technology Inc., USA).

\section{Virus neutralisation test}

MDCK cells were grown to confluence in 24-well plates. Replicates of AIV A/Teal/Tunka/7/2010 (H3N8) were diluted in culture media without foetal calf serum to achieve a virus concentration of approximately $1 \times 10^{5}$ PFU in $500 \mu \mathrm{l}$. Then, $500 \mu \mathrm{l}$ of the virus suspension was mixed with $500 \mu \mathrm{l}$ of freshly prepared $2 \%$ extracts of G. decumbens, $H$. erectum, P. bistorta, and Deva-5 or $1 \%$ extracts of T. chebula and M. cochinchinensis. Specific anti-HA antibodies to homologous $\mathrm{H} 3$ subtype of influenza A virus were used as the positive control for neutralisation. The antibodies were bought as a commercial antiserum against influenza virus H3N2 (Research Institute of Influenza, Saint Petersburg, Russian Federation). The antiserum was diluted 1:10 in sterile $\mathrm{ddH}_{2} \mathrm{O}$, and $100 \mu \mathrm{l}$ of diluted serum was mixed with $400 \mu \mathrm{l}$ of maintenance media and $500 \mu \mathrm{l}$ of the virus suspension. The negative control was prepared by mixing $500 \mu \mathrm{l}$ of sterile $\mathrm{ddH}_{2} \mathrm{O}$ with $500 \mu \mathrm{l}$ of the virus suspension. The mixtures were incubated at $37^{\circ} \mathrm{C}$ for $30 \mathrm{~min}$, and then the concentration of infectious virus in each sample was established using plaque assays. The neutralisation index was estimated as the quotient of the AIV concentration in the negative control to the AIV concentration in the test sample. This test was performed with six independent repeats.

\section{Plaque reduction neutralisation test (PRNT)}

The $2 \%$ extracts of G. decumbens, $H$. erectum, P. bistorta and Deva-5 or $1 \%$ extracts of $T$. chebula and $M$. cochinchinensis were serially diluted two-fold to a concentration of $0.016 \%$ in DMEM media supplemented with $25 \mathrm{mM}$ HEPES, $0.2 \%$ bovine serum albumin, $2 \mu \mathrm{g} /$ $\mathrm{ml}$ of TPCK-trypsin and antibiotics. Sterile $\mathrm{ddH}_{2} \mathrm{O}$ and the specific antihaemagglutin antibodies to the homologous H3 subtype of Influenza A virus were used as controls as described above. Each dilution of the extracts and controls was supplemented with approximately 200
PFU of A/Teal/Tunka/7/2010 (H3N8) virus and incubated at $37^{\circ} \mathrm{C}$ for $30 \mathrm{~min}$. Afterwards, each sample was placed into the wells of 12 - or 24 -well plates with a $90 \%$ confluent monolayer of MDCK cells. Adsorption was conducted at room temperature for $60 \mathrm{~min}$, and then the inocula were discarded and monolayers were covered with overlay media for the plaque assay. At day 3 post infection, the cells were fixed, and the plaques were visualised with crystal violet and counted. Four independent repeats were done for plaque reduction neutralisation test. The $50 \%$ and $90 \%$ inhibition doses were estimated for each extract as the maximal reciprocal dilution of extract that inhibited plaque formation by $50 \%$ or $90 \%$ (ID50\% and ID $90 \%$, respectively).

\section{Data analysis}

Results are presented as the mean value of at least four independent repeats. The standard deviation of the mean was used to evaluate the variability of data. The KolmogorovSmirnof test was used to check the normality of the sample, and Student's t-test was used to evaluate differences between samples. A value of $\mathrm{p} \leq 0.05$ was considered statistically significant. The ID50\% and ID90\% were estimated using probit analysis. The relationship between the concentration of extracts and infectivity of the treated virus was evaluated using the Pearson correlation test. The correlation was assumed to be significant at $R>0.7 \quad(p=0.05)$. Data analysis was performed using Statistica 6.1 and MSOffice EXCEL 2003 software.

\section{Results}

\section{Virus subtype and culture properties}

The isolate A/Teal/Tunka/7/2010 (H3N8) caused a clear cytopathic effect in MDCK cells on day 3 post infection. At this time, it produced small $(0.3-0.5 \mathrm{~mm})$ plaques and reached a titre of $1 \pm 0.2 \times 10^{6} \mathrm{PFU} / \mathrm{ml}$. The subtypespecific RT-PCR produced a single band with primers corresponding to the HA subtype $\mathrm{H} 3$. The phylogenetic analysis of the fragments of HA and NA genes had shown that isolate A/Teal/Tunka/7/2010 (H3N8) has HA of the H3 subtype and NA of the N8 subtype (Figure 1).

\section{Plant extracts are toxic for MDCK cells at concentrations higher than $2 \%$}

All plant extracts were toxic to MDCK cells at concentrations higher than $2 \%$. The most toxic extracts were derived from $T$. chebula and M. cochinchinensis, causing 


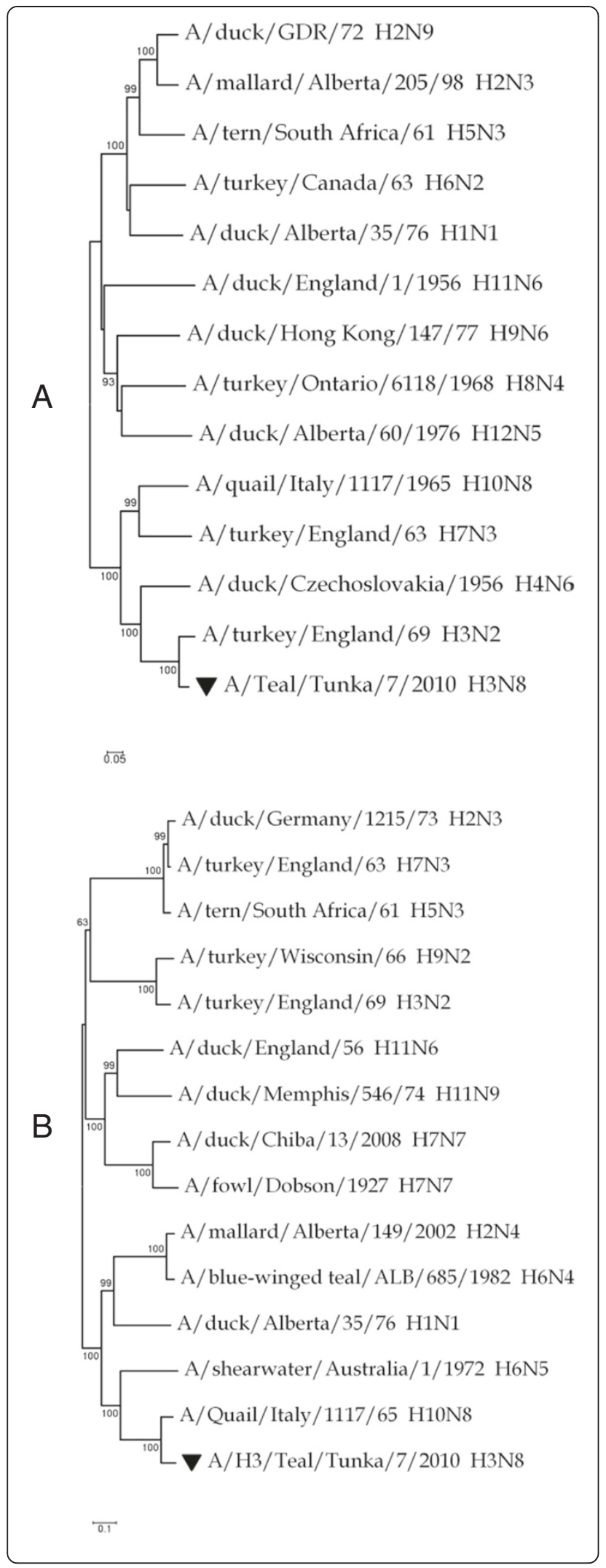

Figure 1 Identification of subtype of influenza $A$ virus isolate A/Teal/Tunka/7/2010. A - phylogenetic analysis of a 714 bp fragment of the HA gene; $\mathbf{B}$ - phylogenetic analysis of a $1216 \mathrm{bp}$ fragment of the NA gene. The sequences of A/Teal/Tunka/7/2010 are labelled with inverted triangles. The phylogenetic analysis was performed using the neighbour-joining method; the estimation of evolutionary distances was made on the basis of the Tamura-Nei 93 model of evolution Tamura and Nei [26]. The significance of trees was evaluated by bootstrap analysis with 1000 replications.

changes in cell morphology at concentrations as low as $0.06 \%$. Plant extracts from P. bistorta and the Deva-5 composition were less toxic, as single MDCK cells were detected under the light microscope when the culture media contained up to $7.5 \%$ of those preparations, although no cells survived at higher concentrations. The results of the cell viability assay at concentrations of plant extracts less than $2 \%$ are presented in Figure 2.

The cytotoxic effect was dose-dependent, and the plant extracts had different cytotoxic profiles. Thus, the highly toxic extracts of $T$. chebula and M. cochinchinensis killed up to $100 \%$ of cells, except for the very low concentrations of $0.5 \%$ and $0.13 \%$, respectively. At higher dilutions, these preparations caused a dose-dependent increase in cell viability and became non-toxic at concentrations of $0.13 \%$ and $0.03 \%$, respectively. The extracts of G. decumbens, P. bistorta and Deva-5 expressed weak cytopathic effects and did not cause significant damage to cells at concentrations of $2 \%$ and less. The extracts of $H$. erectum destroyed $80 \%$ of cells at $2 \%$, but after being diluted only twice, they caused no significant cytopathic effects. These results suggest that extracts of G. decumbens, H. erectum, P. bistorta and Deva-5 have no significant toxicity at concentrations of $2 \%$ and less, whereas extracts of $T$. chebula and $M$. cochinchinensis were well-tolerated by MDCK cells at concentrations $0.13 \%$ and $0.03 \%$, respectively.

\section{Virus neutralisation by plant extracts}

Treatment of high doses of virus with high concentrations of plant extracts did not affect the infectivity of virus, with the exception of extracts of $H$. erectum, $M$. cochinchinensis and T. chebula. These three extracts significantly reduced the infectivity of $\mathrm{A} / \mathrm{Teal} / \mathrm{Tunka} / 7 /$ 2010 (H3N8) by approximately five-fold (Figure 3). The specific antibodies reduced virus infectivity by 100 -fold, which indicates the weak neutralising ability of these plant extracts.

The plaque reduction neutralisation tests revealed that none of the extracts were able to inhibit plaque formation by $90 \%$. However, three extracts, i.e. H. erectum, T. chebula and M. cochinchinensis, inhibited plaque formation by more than $50 \%$ at low dilutions, i.e. from 1:3 to 1:14 (Table 2). Specific antibodies to the H3 subtype 


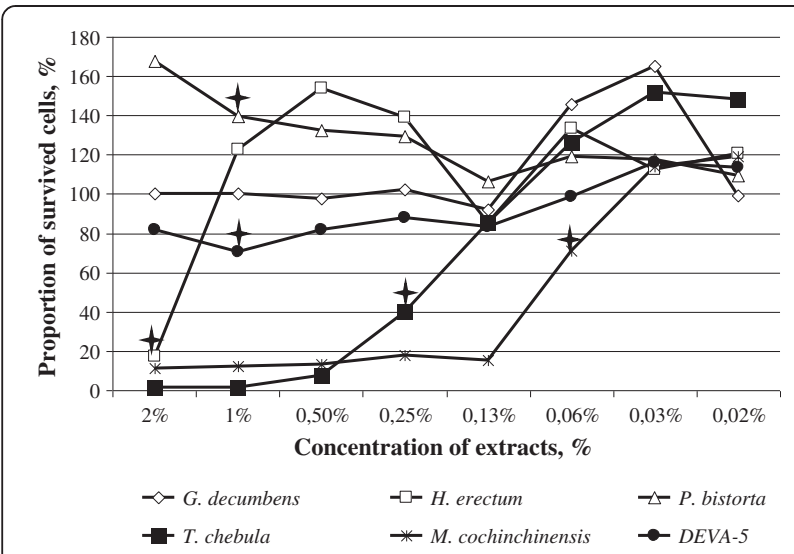

Figure 2 Viability of MDCK cells (\%) treated with different concentrations of plant extracts. The lowest concentration at which toxic (or enhancing) effects reach statistical significance $(p<0.05)$ are labelled by quadrangular stars. influenza virus inhibited plaque formation by $90 \%$ at a dilution of $1: 6($ ID90\% = 6) and plaque formation by $50 \%$ at a dilution of 1:60 (ID50\%=59.1). Only one preparation, $T$. chebula, exhibited a significant positive correlation $(\mathrm{R}>0.7$ at $\mathrm{p}=0.05)$ between the dilution factor of the extract and the infectivity of the virus (Figure 4). These results are summarised in Table 2 where the neutralisation indexes and 50\% inhibition doses are given.

\section{Discussion}

Deva-5 is used in traditional medicine to treat infectious diseases, including seasonal and epidemic flu. G. decumbens and $H$. erectum have been described as antimicrobial herbs

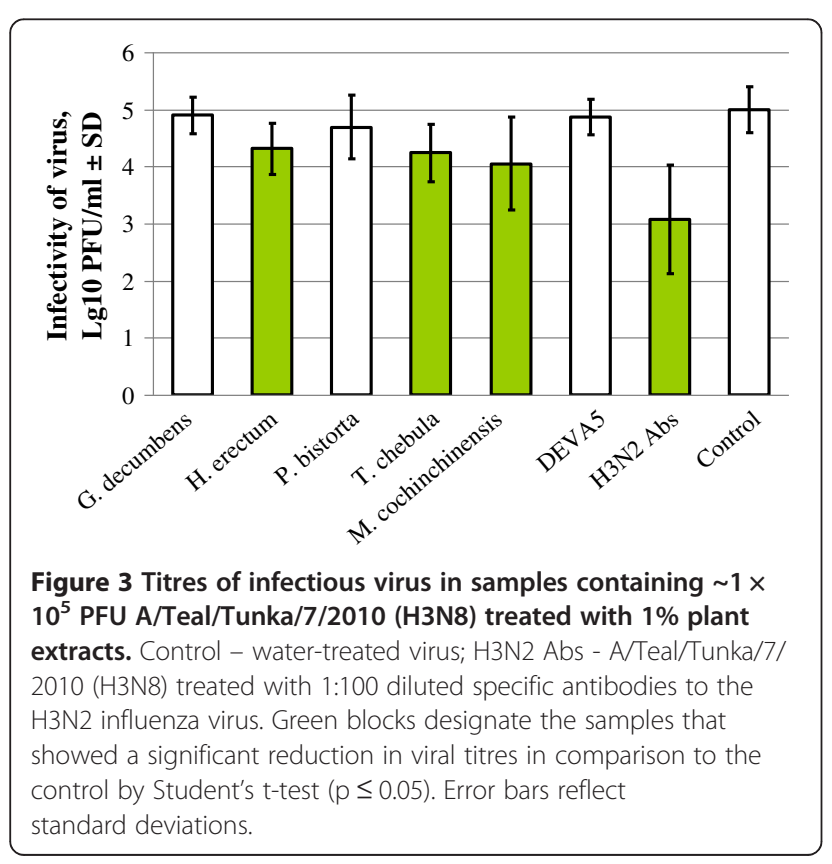

Table 2 Direct antiviral action of plant extracts against influenza $A$ virus A/Teal/Tunka/7/2010 (H3N8)

\begin{tabular}{lll}
\hline Extract & $\mathbf{N I} \pm$ SD $^{*}$ & ID50\% \\
\hline Gentiana decumbens, 1\% extract & $1.4 \pm 0.7$ & - \\
Hypecoum erectum, 1\% extract & $4.8 \pm 0.2$ & 8.6 \\
Polygonum bistorta, 1\% extract & $1.6 \pm 0.1$ & - \\
Terminalia chebula, 0.5\% extract & $4.9 \pm 0.2$ & 13.4 \\
Momordica cochinchinensis, 0.5\% extract & $5.1 \pm 0.3$ & 2.7 \\
DEVA-5, 1\% extract & $1.6 \pm 0.4$ & - \\
H3N2 Abs, diluted as 1:100 & $93.9 \pm 0.7$ & 59.1
\end{tabular}

* - approximately $1 \times 10^{5}$ PFU of A/Teal/Tunka/7/2010 (H3N8) were used for the $\mathrm{Nl}$ assay.

** - approximately 200 PFU of A/Teal/Tunka/7/2010 (H3N8) were used for the PRNT assay.

The neutralisation index (NI) was estimated as the quotient of the virus concentration in the water-treated sample to the virus concentration in the test sample. The $50 \%$ inhibition dose was estimated using probit analysis as the maximal reciprocal dilution of extract that inhibited the formation of plaques by $50 \%$.

in books of traditional medicine [9]. In this study, we tested the antiviral activities of the traditional drug Deva- 5 and its components against avian influenza virus H3N8 in cell culture. The virus strain A/Teal/Tunka/7/2010 (H3N8) used in our study was previously characterised in a very restricted set of experiments. Therefore, we sequenced the HA and NA genes to exclude possible misidentification of the virus subtype or the misplacement of virus stock. The genetic identification of the virus subtype was performed by phylogenetic analysis in comparison with reference strains of each subtype and confirmed the virus identity.

Although Deva-5 did not show concentration-dependent antiviral activity, some signs of virus inhibition by Deva- 5 were observed at the $1 \%$ concentration of the extract (Figure 4). This effect can be explained by the presence of three components that consistently reduced the infectivity of A/Teal/Tunka/7/2010 (H3N8): H. erectum and T. chebula and M. cochinchinensis. These three extracts inhibited the virus much more weakly than specific anti-HA antibodies; however, this may have been due to the very low concentrations of bioactive substances in the water extracts. For example, in similar research on Scutellaria baicalensis, the authors used $30 \mathrm{~g}$ of a crude powder treated with $200 \mathrm{ml}$ of various organic solvents. Afterwards, the preparations were freeze-dried, and working solutions with concentrations of extract equal to $1 \mathrm{mg} / \mathrm{ml}$ were prepared. Under these conditions, the $\mathrm{IC}_{50}$ in PRNT against IAV H1N1 varied from $14 \mu \mathrm{g} / \mathrm{ml}$ to $134 \mu \mathrm{g} / \mathrm{ml}$ [27]; this approximately corresponds to a reciprocal dilution from 10 to 100. In our research, we used only 1-2 grams of homogenised herbs or seeds, and in the PRNT these extracts exhibited an $\mathrm{IC}_{50}$ equal to a reciprocal dilution between 8 and 14. So, it is likely that, if the concentration of biologically active components had been increased (e.g. by freeze-drying, or with chemical fractionation to remove toxic substances), the 

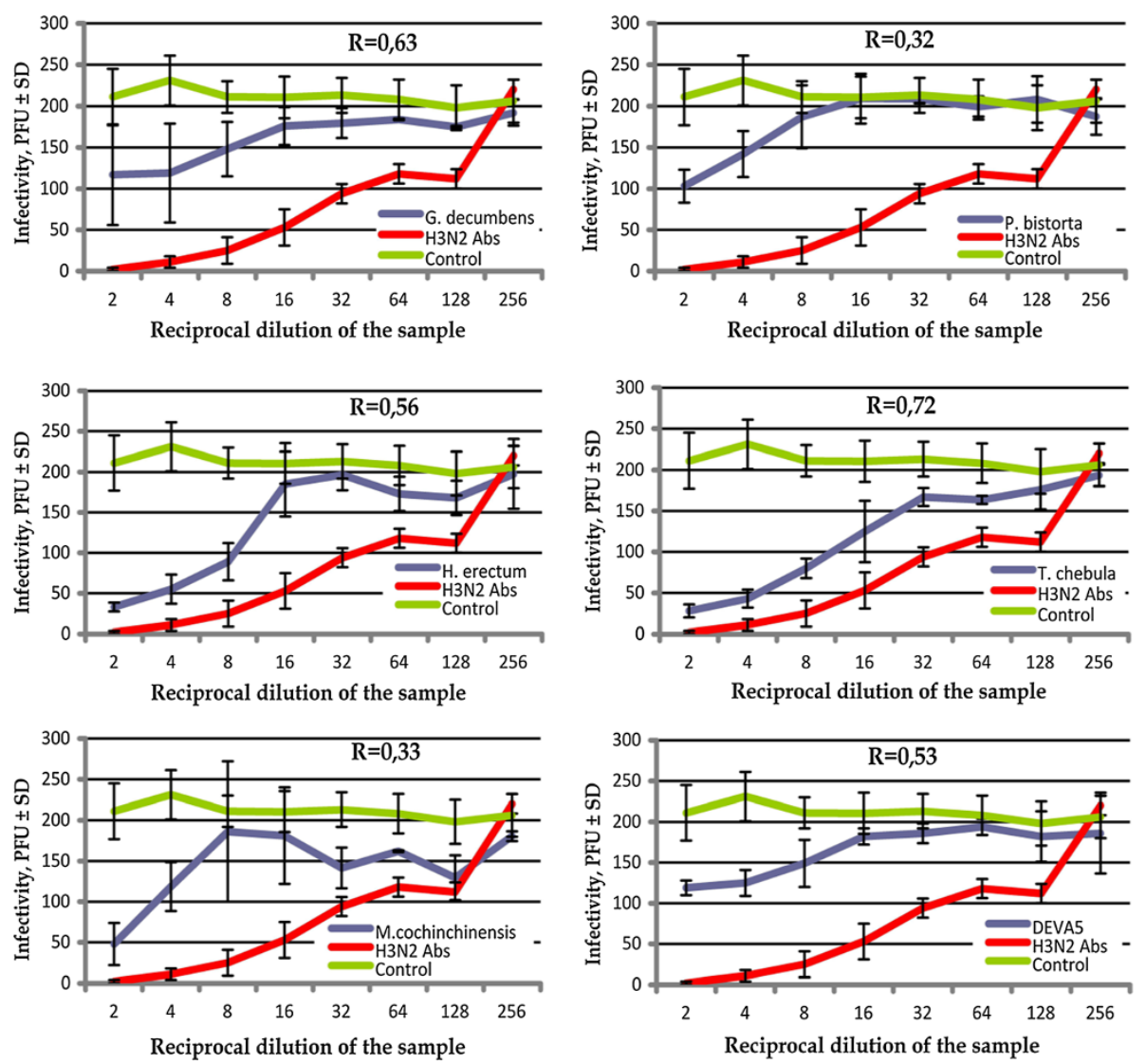

Figure 4 Neutralising activity of different concentrations of plant extracts against influenza A virus A/Teal/Tunka/7/2010 (H3N8). Red line - specific antibodies to the H3 subtype of influenza A virus; green - non-treated virus; blue - virus treated with the corresponding plant extract. The data reflect the mean values of four independent repeats of the PRNT assay as described in the Methods; error bars show standard deviations. The correlation coefficients $R$ between the reciprocal dilution of extracts and infectivity of A/Teal/Tunka/7/2010 (H3N8) are shown in each panel. The correlation was assumed to be statistically significant at $R>0.7(p=0.05)$.

antiviral properties would have become stronger as well. Thus, although Deva-5 and its constituents have extremely low antiviral activity, if any, the extracts of $H$. erectum, $T$. chebula and $M$. cochinchinensis are promising potential sources of new antiviral drugs.

Deva-5 exhibited weak cytotoxicity and did not cause significant damage to MDCK cells at concentrations less than $2 \%$. The possible rationale for the use of Deva-5 instead of separate plant extracts is the cumulative effect of the action of its constituents. Indeed, the extracts of $H$. erectum, T. chebula and M. cochinchinensis exhibited antiviral action, but were also quite toxic to mammalian cells (Figure 2). In contrast, the extracts of $G$. decumbens and P. bistorta exhibited no antiviral action, but possessed very low cytotoxicity. Moreover, an approximate increase of $60 \%$ in the cell number in samples treated with extracts of $P$. bistorta suggests that this constituent may have a stimulating effect on mammalian cell growth (Figure 2). Thus, Deva-5 consists of two types of components: "antivirals" that exert inhibition of the virus but also destroy mammalian cells; and "cell protectors" that compensate for the negative effects of antiviral constituents.

It has been previously reported that the $H$. erectum plant contains steroidal saponins, alkaloids, and coumarins [14]. However, no antiviral substances have been isolated from this plant. Likewise, no reports have been published on antiviral constituents isolated from M. cochinchinensis. This plant was shown to contain momorchochin, alkenes, fatty acids, carotenoids, triterpenoidal saponins, cochinin B and a specific chymotripsin inhibitor. Three other plants have been reported to contain phenolic compounds and flavonoids that possess strong anti-influenza viral activity [12]. In addition G. decumbens contains secoiridoids and alkaloids, P. bistorta contains fatty acids, steroids and triterpenoids, and T. chebula contains fatty acids, fructose, amino acids, anthraquinone and triterpenoids [17]. The protective activity of $T$. chebula against influenza A virus (H1N1) has been reported; however, in contrast to our findings, no direct antiviral activity of the water extract of $T$. chebula was detected in this study [19]. This discrepancy may have been caused by the different subtype of IAV used in our study 
(H3N8). In this case, the antiviral substances of T. chebula might have a subtype-specific inhibitory activity against IAV. Further research is necessary to resolve this question. Thus, for the first time, the direct antiviral action of two components of the Deva- 5 herb formulation, $H$. erectum and T. chebula, was demonstrated in this work.

Our preliminary study showed that Deva- 5 inhibited the growth of Staphylococcus aureus. Hexane and dichloromethane extracts from $M$. cochinchinensis leaves, as well as seven alkaloids isolated from $H$. erectum, have antimicrobial activity against a number of Gram-negative and Gram-positive bacteria, including Staphylococcus aureus $[28,14]$. Bag et al. showed that a hot aqueous extract of $T$. chebula fruit was found to be potent against Staphylococcus aureus strains, whereas an ethanol extract was found to be more potent against Escherichia coli strains [18]. Also, an aqueous extract of $T$. chebula exhibited antifungal activity against a number of dermatophytes and pathogenic yeasts and the acetone extract of $T$. chebula seeds showed antiplasmodial activity against Plasmodium falciparum [18]. Taken together, these results suggest that rationality of the use of Deva- 5 in traditional medicine to treat infectious diseases can be explained by the antiviral and antimicrobial properties of its components.

\section{Conclusions}

For the first time, the consistent direct antiviral action of extracts of $H$. erectum, $T$. chebula and $M$. cochinchinensis was demonstrated. These extracts significantly reduced the infectiveness of influenza A virus H3N8 in vitro when used at high concentrations $(0.25-1 \%)$. However, Deva- 5 itself and the remainder of its components did not exhibit significant antiviral activity. These results suggest that the former three plants contain substances with significant antiviral activity and could be a promising source of new antiviral drugs. However, further research, including in vivo tests in an animal model, is necessary to identify the biologically active components and to remove toxic substances.

\section{Abbreviations \\ IAV: Influenza A virus; AIV: Avian influenza virus; HA: Haemagglutinin; NA: Neuraminidase.}

\section{Competing interests}

The authors declare that they have no competing interests.

\section{Authors' contributions}

NO conceived the study, performed the preparation of extracts, participated in study design, participated in data analysis and interpretation and wrote the manuscript; MAK designed the study, performed the virological experiments, participated in the molecular genetic studies, carried out data analysis and interpretation and wrote the manuscript; AVL carried out the molecular, genetic and virological studies, participated in data analysis and critically discussed the manuscript; GAD, JO, CC, SO, PM and JB participated in study design and coordination and helped to interpret the results and draft the manuscript. All authors contributed to manuscript preparation and approved the final manuscript.

\section{Acknowledgements}

This study was funded by the Fund of Science and Technology, Ministry of Education and Science of Mongolia.

The authors are grateful to technician Ekatirina P. Gladkova (Scientific Centre of Family Health and Human Reproduction Problems of Siberian Branch of the Russian Academy of Medical Sciences. K. Marks Str. 3, Irkutsk. 664025, Russian Federation) for excellent technical support.

\section{Author details}

${ }^{1}$ Institute of Traditional Medicine, Mongolian National University of Medical Sciences, Zorig str, Sukhbaatar district, Ulaanbaatar, Mongolia. ${ }^{2}$ Federal State Public Institution Scientific Centre of Family Health and Human Reproduction Problems Siberian Branch of Russian Academy of Medical Sciences, K. Marks Str. 3, Irkutsk, Russian Federation. ${ }^{3}$ National Centre for Public Health, Ministry of Health, Peace Avenue-17, Bayanzurkh district, Ulaanbaatar, Mongolia. ${ }^{4}$ Traditional Medical Science Technology and Production Corporation of Mongolia, Khan Uul district, Chinggis Avenue, Ulaanbaatar 17032, Mongolia.

Received: 25 November 2013 Accepted: 23 June 2014

Published: 10 July 2014

\section{References}

1. Darmaa B, Burmaa, Naranzul T, Bayasgalan N, Enkhsaikhan D, Maitsetseg C, Nyama G, Tserendulam B, Enkhbaatar L, Gantsooj B, Urtnasan C, Nyamdavaa P: Influenza morbidity and surveillance results in Mongolia in 2010/2011 season. Mong J of Infect Dis Res 2011, 3(40):2-6.

2. Tong S, Li Y, Rivailler P, Conrardy C, Castillo DA, Chen LM, Recuenco S, Ellison JA, Davis CT, York IA, Turmelle AS, Moran D, Rogers S, Shi M, Tao Y, Weil MR, Tang K, Rowe LA, Sammons S, Xu X, Frace M, Lindblade KA, Cox $\mathrm{NJ}$, Anderson $L$, Rupprecht $C E$, Donis RO: A distinct lineage of influenza A virus from bats. Proc Natl Acad Sci 2012, 109(11):4269-74.

3. Webster RG, Bean WJ, Gorman OT, Chambers TM, Kawaoka Y: Evolution and ecology of influenza A viruses. Microbiol Rev 1992, 56(1):152-79.

4. World Health Organization: Summary of the 2011-2012 influenza season in the WHO European region. 2012. http://www.euro.who.int/_data/assets/ pdf_file/0008/168866/Season-overview-2011-2012_9 Jul-2012_FINAL.pdf .

5. Guo Y, Wang M, Kawaoka Y, Gorman O, Ito T, Saito T, Webster RG: Characterization of a new avian-like influenza $A$ virus from horses in China. Virology 1992, 188(1):245-55.

6. Yondon M, Heil GL, Burks JP, Zayat B, Waltzek TB, Jamiyan BO, McKenzie PP, Krueger WS, Friary JA, Gray GC: Isolation and characterization of H3N8 equine influenza A virus associated with the 2011 epizootic in Mongolia. Influenza Other Respir Viruses 2013, 7(5):659-65.

7. Tumurbaatar N: Hot-Natured Disorders in Traditional Mongolian Medicine, Volume 19. Ulaanbaatar: Eruul enkh press; 1998:92.

8. Manag rinchin junai: Traditional Medical source book. People's Republic of China: "Inner Mongolian medical treasurers" printing house; 1978:179.

9. Ligaa U, Davaasuren B, Ninjil N: Mongolian Medicinal Plants Using in Western and Eastern Medicine. Ulaanbaatar: JKC printing; 2005:121-122. 326, 438.

10. Myagmar $\mathrm{BE}$, Aniya $\mathrm{Y}$ : Free radical scavenging action of medicinal herbs from Mongolia. Phytomedicine 2000, 7:221-9.

11. Jung K, Chin YW, Yoon K, Chae HS, Kim CY, Yoo H, Kim J: Antiinflammatory properties of a triterpenoidal glycoside from Momordica cochinchinensis in LPS-stimulated macrophages. Immunopharmacol Immunotoxicol 2013, 35:8-14.

12. Tsoi AY, Ng TB, Fong WP: Antioxidative effect of a chymotrypsin inhibitor from Momordica cochinchinensis (Cucurbitaceae) seeds in a primary rat hepatocyte culture. J Pept Sci 2005, 11(10):665-8.

13. Juthamas C, Kohei O, Hiroaki S, Ikuo S, Wichet L: Cochinin B, a Novel Ribosome-Inactivating Protein from the Seeds of Momordica cochinchinensis. Biol Pharm Bull 2007, 30(3):428-432.

14. Yinfen S, Shengkun L, Na L, Liling C, Jiwen Z, Junru W: Seven alkaloids and their antibacterial activity from Hypecoum erectum L. J Med Plants Res 2011, 5(22):5428-5432.

15. Deok SB, Young HK, Cheol HP, Chu WN, Javzan S, Jamyansan YA, Jae KL: Protopine reduces the inflammatory activity of lipopolysaccharidestimulated murine macrophages. BMB Rep 2012, 45(2):108-113.

16. Duwiejua M, Zeitlin IJ, Waterman PG, Gray Al: Anti-inflammatory activity of Polygonum bistorta, Guaiacum officinale and Hamamelis virginiana in rats. J Pharm Pharmacol 1994, 46:286-90. 
17. Anwesa B, Subir KB, Rabi RC: The development of Terminalia chebula Retz. (Combretaceae) in clinical research. Asian Pac J Trop Biomed 2013, 3:244-252.

18. Anwesa B, Subir KB, Premananda B, Nishith KP, Ranjan R, Rabi Ranjan C: Evaluation of antibacterial properties of Chebulic myrobalan (fruit of Terminalia chebula Retz.) extracts against methicillin resistant Staphylococcus aureus and trimethoprim-sulphamethoxazole resistant uropathogenic Escherichia coli. Afr J Plant Sci 2009, 3(2):025-029.

19. Badmaev V, Nowakowski M: Protection of epithelial cells against influenza A virus by a plant derived biological response modifier ledretan- 96 . Phytother Res 2000, 14:245-249.

20. World Health Organization: Manual on Animal Influenza Diagnosis and Surveillance. Switzerland, Geneva: WHO Department of Communicable Diseases Surveillance and Control; 2002. WHO/CDS/CSR/NCS/WHO: 2002:1-98. 5 Rev.

21. Gaush CR, Smith TF: Replication and plaque assay of influenza virus in an established line of canine kidney cells. Appl Microbiol 1968, 16(4):588-594.

22. Payungporn S, Phakdeewirot P, Chutinimitkul S, Theamboonlers A, Keawcharoen J, Oraveerakul K, Amonsin A, Poovorawan Y: Single-step multiplex reverse transcription-polymerase chain reaction (RT-PCR) for influenza A virus subtype H5N1 detection. Viral Immunol 2004, 17(4):588-93.

23. Tsukamoto K, Ashizawa H, Nakanishi K, Kaji N, Suzuki K, Okamatsu M, Yamaguchi S, Mase M: Subtyping of $\mathrm{H} 1$ to $\mathrm{H} 15$ hemagglutinin genes of avian influenza virus by RT-PCR assay 4 and molecular determination of the pathogenic potential. J Clin Microbiol 2008, 46(9):3048-55.

24. World Health Organization: A revision of the system of nomenclature for influenza viruses: a WHO Memorandum. Bull World Health Org 1980, 58(4):585-591.

25. Hoffmann E, Stech J, Guan Y, Webster RG, Perez DR: Universal primer set for the full-length amplification of all influenza A viruses. Arch Virol 2001, 146(12):2275-89

26. Tamura K, Nei M: Estimation of the number of nucleotide substitutions in the control region of mitochondrial DNA in humans and chimpanzees. Mol Biol Evol 1993, 10:512-526.

27. Hour MJ, Huang SH, Chang CY, Lin YK, Wang CY, Chang YS, Lin CW: Baicalein, ethyl acetate, and chloroform extracts of Scutellaria baicalensis inhibit the neuraminidase activity of pandemic $2009 \mathrm{H} 1 \mathrm{~N} 1$ and seasonal influenza A viruses. Evid Based Complement Alternat Med 2013, 2013:750803. doi:10.1155/2013/750803.

28. Khesorn N, Patoomratana T: Antimicrobial activity of hexane and dichloromethane extracts from Momordica cochinchinensis (Lour.) Spreng Leaves. Thai Pharm Health Sci J 2009, 4:15-20.

doi:10.1186/1472-6882-14-235

Cite this article as: Oyuntsetseg et al:: Evaluation of direct antiviral activity of the Deva-5 herb formulation and extracts of five Asian plants against influenza A virus H3N8. BMC Complementany and Alternative Medicine 2014 14:235.

\section{Submit your next manuscript to BioMed Central and take full advantage of:}

- Convenient online submission

- Thorough peer review

- No space constraints or color figure charges

- Immediate publication on acceptance

- Inclusion in PubMed, CAS, Scopus and Google Scholar

- Research which is freely available for redistribution 